\title{
Thalamic Tumor Presenting as Major Depression and Headache
}

Robert Jay Claire, M.D.

Cedars-Sinai Medical Center, Los Angeles, California

Follow this and additional works at: https://jdc.jefferson.edu/jeffjpsychiatry

Part of the Psychiatry Commons

Let us know how access to this document benefits you

\section{Recommended Citation}

Claire, M.D., Robert Jay (1993) "Thalamic Tumor Presenting as Major Depression and Headache," Jefferson Journal of Psychiatry. Vol. 11 : Iss. 1 , Article 11.

DOI: https://doi.org/10.29046/JJP.011.1.014

Available at: https://jdc.jefferson.edu/jeffjpsychiatry/vol11/iss1/11

This Article is brought to you for free and open access by the Jefferson Digital Commons. The Jefferson Digital Commons is a service of Thomas Jefferson University's Center for Teaching and Learning (CTL). The Commons is a showcase for Jefferson books and journals, peer-reviewed scholarly publications, unique historical collections from the University archives, and teaching tools. The Jefferson Digital Commons allows researchers and interested readers anywhere in the world to learn about and keep up to date with Jefferson scholarship. This article has been accepted for inclusion in Jefferson Journal of Psychiatry by an authorized administrator of the Jefferson Digital Commons. For more information, please contact: JeffersonDigitalCommons@jefferson.edu. 


\title{
Brief Report
}

\section{Thalamic Tumor Presenting as Major Depression and Headache}

\author{
Robert Jay Claire, M.D.
}

We report the case of a 39 year old male who presented with Major Depression, headache, and apathy. Within six weeks of his initial presentation the patient died from a "Central Herniation Syndrome" after biopsy of a left thalamic lesion. The statistics of medical problems presenting as psychiatric disorders as well as recent literature on personality changes associated with thalamic infiltration are reviewed.

It is recognized that from $33-80 \%$ of inpatient psychiatric patients have concurrent medical disease. A large proportion of these are unrecognized prior to psychiatric hospitalization (1). In 1983, Martin clearly stated that "psychiatric symptoms are often the earliest and occasionally the only symptoms of intracranial tumor." Martin also reported that slow growing tumors were associated with depression and personality changes. Primary tumors of the thalamus were described by Smyth and Stern over fifty years ago when they described that these patients had a flat affect, decreased verbal output and apathy (3).

\section{CASE REPORT}

Mr. A was a thirty nine year old white male, who presented at a Veterans Outreach Center with feelings of abandonment, hopelessness, helplessness and worthlessness. He had a four week history of depressed mood manifested by hypersonmolence (sleeping up to twenty hours a day), loss of interest in personal hygiene, and difficulty concentrating. Mr. A could not follow sporting events on television for more than ten minutes. Mr. A had a well organized plan for suicide. He planned to wait until his wife graduated from nursing school, and while she was visiting her parents with their children, he was going to shoot himself in the head.

At the time of this initial presentation he complained of global headaches, diplopia, blurry vision, and vertigo. Two weeks before his presentation to us, he was seen at a Health Maintenance Organization where he was diagnosed as having anxiety and started on alprazolam.

Mr. A's only other contact with psychiatry was one and one half years before this presentation. He complained of being impulsive and irritable. Mr. A was felt to have P.T.S.D. and a possible impulse control disorder. He elected not to return for further psychiatric evaluation and treatment at that time. 


\section{Mental Status Exam}

Mr. A presented as a thirty nine year old obese male who made poor eye contact. His speech was noted to be slightly pressured and tangential, but goal directed. Mr. A's mood was depressed and his affect was flat. His thought processes included constant ruminations about "being strong minded" (which he used interchangeably with strong willed). There were some elements of both thought broadcasting and thought blocking.

Mr. A demonstrated some mild cognitive impairment, and he also gave up easily on all tasks. He insight was felt to be impaired.

\section{Clinical Course}

Mr. A was admitted to an inpatient psychiatric unit with diagnosis of Atypical Major Depression and a recommendation for evaluation for possible brain mass. While an inpatient he was noted to be impulsive and irritable, with suicidal ideation, hypersomnalence, flat affect, ten pound weight loss and cognitive impairment.

During his hospitalization Mr. A was started on imipramine and titrated to a dose of $125 \mathrm{mg}$. at bedtime. There was a moderate clinical response to the medication with Mr. A sleeping less, being more energetic and less apathetic. No serum levels were obtained and the inpatient staff failed to order neuro imaging studies. Except for the mental status abnormalities noted here no gross neurological findings were noted.

After discharge Mr. A was seen in the outpatient clinic with some improvement in his depressive symptoms, but he complained of intermittent headache, diploplia, and vertigo. A CAT scan of the brain was ordered, however before it could be performed Mr. A presented to the urgent care area with complaint of severe headache, depression and apathy. A lumbar puncture was performed revealing: glucose 59, protein 90 ( $\mathrm{nl}$ 15-45), 2 RBC, 14 WBC, 4 Polys, 59 Lymph, and 37 Histiocytes. The patient was admitted to the Neurology Service.

The physical exam was unremarkable. A repeat lumbar puncture yielded a glucose of 58 and a protein of 112. The CAT scan of the brain revealed a left subcortical enhancing lesion abutting the thalamic region. An MRI of the brain with gadolinium enhancement demonstrated a subcortical mass extending into the thalamus and left lateral ventricle. Neuropsychological evaluation was compatible with psychomotor slowing, variable attention span, defecits with abstract reasoning, all consistent with a subcortical lesion.

Mr. A was transferred to the Neurosurgical Service where stereotactic biopsy was performed. The pathology specimen demonstrated gliobastoma multiforme. Postoperatively the patient was even more drowsy and lethargic than he had been preoperatively. When left alone Mr. A would immediately dose off. He required extra stimulation to maintain wakefulness. When awake Mr. A would be oriented to three spheres and was able to comprehend what was happening to him. The nursing staff noted a decrease in verbal output. Mr. A went on to develop expressive aphasia, 
neologisms, and paraphrasia. He had frank visual field defects and right homonymous hemianopsia. A right hemianesthesia was also present. He had clear optic disc borders on fundoscopy and a decrease in venous pulsation.

Mr. A's deterioration was attributed to post operative edema, as well as bleeding from the biopsy site. A brain CAT scan was done postoperatively, which revealed blood in the operative site and swelling in the area of the tumor bed. A slight enlargement of the ventricles was also observed. He was aggressively treated for cerebral edema, with moderate improvement. Treatment options were discussed with Mr. A and his family, including VP shunt, radiation to the tumor and/or resection of the tumor. The patient and his family opted for no further intervention. Mr. A died of central herniation six weeks after his initial presentation.

\section{DISCUSSION}

Gutmann et al recently reported a case of "Personality changes associated with thalamic infiltration," involving a twenty seven year old female presenting with personality changes, social withdrawal, blunted affect, diminished verbal output, bradykinesia, and difficulty writing. Unlike Mr. A this patient had bilateral exopthalmus "with an inability to bury her sclerae on extremes of lateral gaze, a transverse smile with normal facial motor function, right handed clumsiness and right sided spatial neglect." There were no other neurological abnormalities with the exception of mental status changes. Gutmann's patient was treated aggressively with dexameth' asone and partial brain irradiation (4). At the time of the article, Gutmann's patient had survived for 20 months.

As early as 1951 Bleuler reported that in six hundred documented cases of brain tumor seventy percent were retrospectively noted to have some degree of psychopathology (4). Galasko et al reported depression or apathy occurring early in the course of seventeen individuals with brain tumors (5).

Lishman underscores that somnolence and hypersomnia are frequent with diencephalic tumors stating that "The hypersomnia due to a diencephalic lesion is essentially an excess of normal sleep and when roused the patient awakens normally and fully" (6).

Our purpose in writing this paper is to underscore the importance of thorough neurological exam and neuro-imaging studies in adults of forty or older who have an initial episode of major psychiatric disorder marked by apathy, hypersomnolence, change in affective state, cognitive impairment, hallucination or delusions (6). We realize that in these days of cost containment our recommendation is controversial, but even at a fifteen percent occurrence rate the saving of lives and dollars are substantial.

\section{ACKNOWLEDGEMENTS}

The opinions expressed in this article are solely those of the author and should not be construed as those of the University of California at Davis or the Department of Veterans Affairs. 
The author would like to thank Deborah S. Claire, R.N., B.S.N., for administrative assistance and Mark E. Servis, M.D., for editorial assistance.

\section{REFERENCES}

1. Spaite, Daniel W and Smith, Roger A: Psychiatric Presentation of Mental Illness. Journal of Emergency Medicine 1987; 5:367-373

2. Martin, Maurice J: A Brief Review of Organic Diseases Masquerading as Functional Illness. Hospital and Community Psychiatry 1983; 34(4):328-332

3. Smyth GE, and Stern K: Tumors of the Thalmus-A ClinicoPathological Study, Brain 1938; 61:339-74

4. Gutmann, David H, Grossman, Robert I and Mollman, Joan E: Personality Changes Associated with Thalamic Infiltration: Journal of Neuro-Oncology 1990; 8:263-267

5. Galasko, Douglas, Kwo-Oh-Yuen PF and Thal, Leon: Intracranial Mass Lesions Associated With Late Onset Psychosis and Depression: Psychiatric Clinics of North America 1988; $1: 151-163$

6. Lishman, Organic Psychiatry, Second Edition, pp 187-199 